\title{
Editorial \\ Retirement Farewell, and Recommendations for the Next Generation of Scientists
}

\author{
Palmiro Poltronieri (D)
}

check for

updates

Citation: Poltronieri, P. Retirement Farewell, and Recommendations for the Next Generation of Scientists. Challenges 2022, 13, 5. https:// doi.org/10.3390/challe13010005

Received: 18 January 2022

Accepted: 7 February 2022

Published: 8 February 2022

Publisher's Note: MDPI stays neutral with regard to jurisdictional claims in published maps and institutional affiliations.

Copyright: (c) 2022 by the author. Licensee MDPI, Basel, Switzerland. This article is an open access article distributed under the terms and conditions of the Creative Commons Attribution (CC BY) license (https:// creativecommons.org/licenses/by/ $4.0 /)$.
National Research Council of Italy, AgroFood Department, Institute of Sciences of Food Productions, 73100 Lecce, Italy; palmiro.poltronieri@ispa.cnr.it

While thematic journals have seen a great increase in submissions that ensure their status of monthly or bi-weekly editions, growing their audience in the scientific community, journals such as Challenges, at the crossroad of various disciplines, have laid their foundations as cross-cultural and interdisciplinary journals.

This journal has become a leading voice for cultural niches, such as local community associations (I proudly report here the article "Indigenous Natural and First Law in Planetary Health"; https:/ / www.mdpi.com/2078-1547/11/2/29 (accessed on 6 February 2022)), as well as public and private stakeholders, governmental agendas, and NGO bodies.

In doing so, Challenges is positioned to magnify and accelerate agreement in the scientific community, to realize alternative activities to solve the main problems afflicting our planet, as stated in the journal objective "Addressing the Environmental, Community, and Health Impacts of Resource Development".

Today, and in the coming years, Challenges will support the identification and will lead in the realization of measures aimed to solve these problems. Standing upon this principle of planetary health improvement, the journal requests contributors to stress the ways in which the submitted articles are relevant to the grand challenges of our time.

In the last five years, I have witnessed a great and positive improvement in the published articles, and in the attitude of the editorial management in supporting the contributors through to the final publication of their work. I have to give thanks to Professor Susan Prescott, who has assisted me as Coeditor-in-Chief, and will continue to be EiC, and also to InVivo, a society affiliated with Challenges since 2019.

I want to leave a legacy to putative candidate writers for articles and other types of submissions. First of all, I recommend you to think and be positive, even when times are unfavorable. We have seen a surge in parties ruling by private interest. In the early XX century, states faced industrial development with a major use of fossil fuels, carbon and petrol. Nowadays, the need to reduce climate deterioration is leading to more sustainable choices, producing energy from renewable biomass and from natural energy sources, while this green revolution may also fuel the introduction of electric cars and motors. This has led to the COP25 meeting in Paris, setting up a preliminary containment of $\mathrm{CO}_{2}$ release, supported by the scientific community asking for protection of the planet. This was followed in 2021 by the COP26 meeting in Glasgow with the implementation of these agreements, and a request to reduce the use of fossil fuels, to limit the increase in temperature of 2 Celsius degrees, by reducing $\mathrm{CO}_{2}$ release into the atmosphere by 2030 .

Secondly, I recommend you to follow European Union Commission publications, that may give you a glimpse on what is going on in fields such as circular economy, bioplastics, waste exploitation, and alternative energies.

In one of the published articles, I found reports on projects I was not aware of (https: / / ec.europa.eu/research-and-innovation/en/horizon-magazine/73-solutions-climate-andbiodiversity-crisis (accessed on 6 February 2022)).

In the Rephyne II project, there are products such as the world largest polymer electrolyte membrane, or PEM, an electrolyser able to produce green hydrogen at scale, a 
technology near to realization, with companies involved in these activities (https: / cordis. europa.eu/project/id/101036970 (accessed on 6 February 2022)). It is important that the authors of contributions sustain their statements with examples from real life, and with abundant references.

Lastly, it is of help to search scientific publications and the Internet for state-of-the-art innovative solutions, such as the storage of energy through the cycling of carbon from a gaseous to liquid state, as reported recently (https:/ / interestingengineering.com/new-co2 -battery-can-halve-the-cost-of-solar-energy-storage (accessed on 6 February 2022)).

Finally, keep in mind the four-letter acronym upon which most impact evaluations are based, SWOT, i.e., strengths, weaknesses, opportunities, and threats, which ensures a technology with an easy pathway for application, or conversely an economic bottleneck, and apply a SWOT also in your article; this may help you in realizing if it will be easily accepted or will generate remarks or confusing statements.

I wish Challenges to enjoy a large development of readership, and awareness of the importance of interdisciplinary discussions focusing on the conservation of our nature, our communities, and of life on earth.

Conflicts of Interest: The author declares no conflict of interest. 